\title{
Penerapan Drainase Biopori dan Kolam Resapan pada lingkungan Perumahan
}

\author{
Akshari Tahir Lopa ${ }^{1}$, Onesimus Sampebua ${ }^{2}$, Anas Arfandi ${ }^{3}$ \\ 1,2,3 Univesitas Negeri Makassar
}

\begin{abstract}
Abstrak. Setiap musim penghujan tiba, air meluap dari saluran drainase pada perumahan Tamarunang Indah yang menyebabkan terjadinya genangan air dan berdampak pada terganggunya aktivitas masyarakat. Hasil identifikasi yang dilakukan bahwa genangan-genangan yang terjadi disebabkan oleh berkurangnya daerah resapan air hujan dan kapasitas saluran drainase yang terbatas dalam menampung debit air yang ada. Selain itu, kebiasaan masyarakat membuang sampah ke saluran drainase menyebabkan saluran drainase tersumbat. Saluran drainase di Perumahan Tamarunang Indah I sebagian besar rusak, telah tertutup, dan kurang terawat. Metode yang akan dipakai dalam mencapai tujuan tersebut adalah sebagai berikut: (1) melakukan penyuluhan pengetahuan tentang cara memelihara drainase lingkungan; metode yang dipakai adalah diskusi dan tanya-jawab; (2) melakukan penyuluhan mengenai pola dan arah aliran drainase lingkungan; metode yang dipakai adalah ceramah, diskusi, dan tanya-jawab; (3) melakukan pelatihan keterampilan pembuatan drainase resapan; metode yang dipakai adalah diskusi, tanya-jawab, demonstrasi, dan latihan; (4) melakukan pelatihan penataan lingkungan; metode yang dipakai adalah diskusi, tanya-jawab, demonstrasi, dan latihan. Seluruh kegiatan program PKM ini direncanakan berlangsung selama delapan bulan dan akan dilakukan evaluasi pada akhir kegiatan. Beberapa hal yang telah dilakukan, antara lain: pemberian penyuluhan dan pelatihan pembuatan drainase resapan yang berwawasan lingkungan, penataan drainase lingkungan, dan pemeliharaan lingkungan perumahan. Hasil telah dilakukan pada kegiatan ini adalah terjadinya peningkatan pengetahuan, cara berfikir dan bertindak, kecakapan, dan mitra dalam memelihara lingkungan perumahan sehingga kondisi lingkungan menjadi bersih, indah, tertata, serta menyehatkan.
\end{abstract}

Kata kunci: Drainase lingkungan, Drainase resapan, Kolam Resapan

\section{PENDAHULUAN}

Perpindahan penduduk pada daerah pinggiran kota memberi dampak pada terjadinya peningkatan rata-rata limpasan air permukaan secara periodic. Hal ini yang selanjutnya berakibat pada peningkatan frekuensi kejadian genangan air dan banjir pada daerah di sekitarnya (Asrib \& Arfandi, 2019). Hal senada telah disampaikan oleh Isik, Kalin, Schoonover, Srivastava, \& Lockaby (2013) bahwa urbanisasi mengakibatkan turunnya jumlah aliran dasar dan peningkatan limpasan. Lebih lanjut, Chu, Knouft, Ghulam, Guzman, \& Pan (2013) menguraikan adanya hubungan antara urbanisasi dengan peningkatan dari frekuensi kejadian debit maksimum air hujan, serta penurunan jumlah dan frekuensi kejadian debit minimum.
Konsep drainase yang secara umum di terapkan di hampir seluruh Indonesia saat ini adalah konsep drainase konvensional. Konsep ini memiliki paradigma penanganan drainase dengan prinsip bahwa seluruh air hujan yang jatuh di suatu wilayah harus secepat-cepatnya dibuang ke saluran drainase. Dengan demikian kemampuan saluran drainase dalam menerima beban dapat melampaui dari kapasitasnya, sehingga air dapat meluap dan dapat mengakibatkan terjadinya genangan air (Maryono, 2020).

Penanganan drainase perkotaan yang masih menerapkan pendekatan lama dengan mengupayakan air cepat mengalir ke bagian hilir dari daerah yang tergenang dan akhirnya dibuang ke sungai, waduk ataupun laut. Hal ini akan menimbulkan terbuangnya sumber daya air secara percuma. Pada beberapa kota besar di Indonesia, 
pemerintah daerah setempat berupaya menyimpan air tanah dengan membuat reservoir bawah tanah di beberapa tempat meskipun biayanya mashih sangat mahal (Sudarmanto, 2010).

Pengendalian debit air hujan merupakan salah satu cara untuk melestarikan air hujan yang jatuh di daerah perkotaan. Hal ini menyesuaikan konsep penanganan drainase yang semakin besar setelah sebagian masyarakat sadar bahwa air di daerah perkotaan merupakan sumber daya yang semakin lama dirasakan semakin langka sehingga perlu dilestarikan (Florince, Arifaini, \& Adha, 2016).

Pengendalian debit air dapat dilaksanakan dengan cara retensi maupun dengan cara infiltrasi. Cara retensi dibagi menjadi dua macam, yaitu "offsite retention", dengan pembuatan kolam, embung, polder atau waduk. Sedangkan "on site retention", misalnya retensi pada atap bangunan, taman, tempat parkir, lapangan terbuka, halaman rumah. Cara infiltrasi dilakukan dengan pembuatan imbuhan buatan pada area tertentu yang bentuknya berupa sumur resapan, parit resapan, wilayah resapan, perkerasan yang lolos air. Namun dalam hal ini harus ada persyaratan bahwa air yang diinfiltrasikan tidak boleh air yang sudah tercemar (Sudarmanto, 2010)

Hal ini juga terjadi pada drainase pada lokasi kegiatan PKM. Munculnya genangan air diberbagai tempat dan debit air yang tidak mampu dialirkan dengan cepat ke saluran drainase menjadi persoalan di lingkungan tersebut. Setiap musim penghujan tiba air meluap dari saluran drainase, dan pada beberapa kejadian menyebabkan terjadi genangan air bahkan masuk ke dalam rumah warga sehingga mengganggu aktivitas masyarakat.

Berdasarkan identifikasi di lapangan, masalah yang terjadi pada lokasi mitra adalah:

1. Genangan-genangan yang terjadi disebabkan oleh berkurangnya daerah resapan air hujan dan kapasitas saluran drainase yang tidak mampu menampung akumulasi air hujan,

2. Perubahan tata guna lahan yang menyebabkan terjadinya peningkatan debit banjir di suatu daerah aliran sistem drainase.

3. Jenis tanah dengan permeabilitas rendah sehingga tingkat resapan air hujan kecil.
4. Perubahan fungsi saluran yang semula adalah saluran irigasi berubah menjadi saluran pembuang (drainase), sehingga elevasi saluran tidak memadai.

5. Lokasi merupakan daerah cekungan.

6. Tersumbatnya saluran oleh endapan, sedimentasi atau timbunan sampah sehingga kapasitas saluran berkurang.

\section{METODE PELAKSANAAN}

Adapun prosedur kerja yang dilakukan untuk mendukung realisasi metode yang dilakukan adalah sebagai berikut:

1. Melakukan pertemuan awal dengan tim pelaksana untuk merencanakan pelaksanaan kegiatan PKM.

2. Melakukan pertemuan awal anggota tim pelaksana dengan kedua mitra program PKM serta pemerintah setempat.

3. Mengurus dan menyampaikan perizinan kepada pemerintah setempat, dalam hal ini Kepala Kelurahan Tamarunang sebagai tempat atau lokasi pelaksanaan kegiatan program PKM.

4. Menyiapkan materi ajar penyuluhan teori maupun pelatihan keterampilan yang akan dilatihkan kepada kedua mitra.

5. Menyediakan bahan dan peralatan yang dibutuhkan untuk menunjang kegiatan penyuluhan dan kegiatan pelatihan keterampilan.

6. Penyuluhan tentang pemeliharaan lingkungan, drainase resapan, pengelolaan dan penataan lingkungan.

7. Survey dan pemetaan arah dan pola aliran drainase untuk membentuk sistim drainase lingkungan yang baik.

8. Demonstrasi dan pelatihan pembuatan drainase resapan, pengelolaan dan penataan lingkungan.

Kegiatan evaluasi Program Kemitraan Masyarakat (PKM) berhasil dengan indikator sebagai berikut:

1. kelompok masyarakat (mitra) yang tinggal pada perumahan Tamarunang Indah I memahami pentingnya drainase lingkungan. 
2. kelompok masyarakat (mitra) akan menerapkan pengetahuan, pengalaman, dan teknologi tepat guna (TTG) yang bersifat praktis, efektif, dan efisien dalam pembuatan drainase resapan.

3. kelompok masyarakat (mitra) berkeinginan untuk menyebarluaskan pembuatan drainase resapan pada masyarakat sekitar perumahan lainnya serta menjelaskan pengelolaan drainase lingkungan.

\section{HASIL DAN PEMBAHASAN}

\section{A. Peta Perumahan dan Arah Aliran Drainase}

Drainase pada perumahan tamarunang indah I selama ini tidak berfungsi sebagaimana mestinya. Arah aliran yang tidak jelas, genangan air yang terjadi serta banyaknya drainase yang tertimbun berdampak pada kerusakan jalan lingkungan serta menjadi sarang nyamuk yang dapat berdampak buruk terhadap kesehatan.

Kegiatan ini diawali dengan melalukan survey topografi untuk mengetahuai elevasi jalan dan dasar saluran drainase. Survey topografi menjadi dasar dalam penyusunan rencana perbaikan arah aliran drainase serta penanggulangan solusi lainnya. Selain itu, kegiatan ini juga melakukan pembuatan peta perumahan secara keseluruhan untuk memahami batas wilayah dan blok rumah yang ada. Hal ini dilakukan atas saran beberapa tokoh masyarakat yang belum mengetahui lokasi blok rumah yang ada di dalam lingkungan perumahan karena tidak adanya peta perumahan.

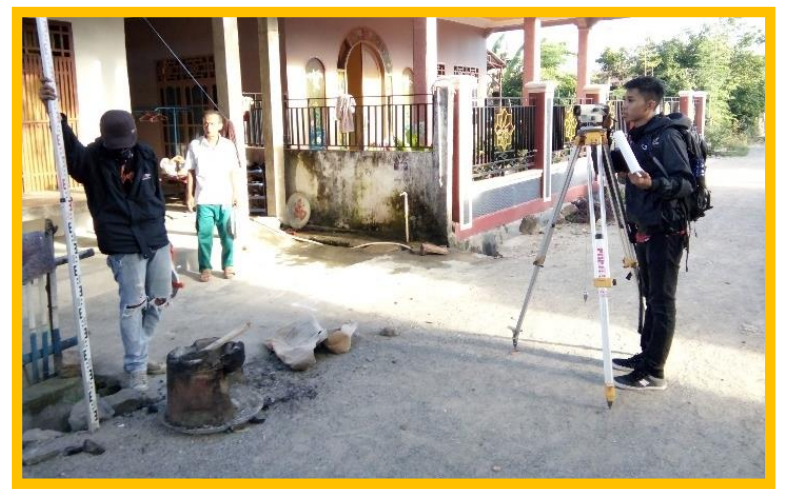

Gambar 1. Survey topografi saluran
Setelah peta perumahan selesai, selanjutnya dilakukan pembuatan peta arah aliran air drainase. Peta arah aliran ini menjadi referensi pemerintah setempat dan warga untuk mengalirkan air nantinya. Arah aliran air juga menjadi bahan evaluasi jaringan drainase yang ada sekarang.

Setelah melakukan survey dan pemetaan diperoleh data pengukuran elevasi dasar saluran, sehingga data tersebut menjadi dasar dalam perencanaan arah aliran air.

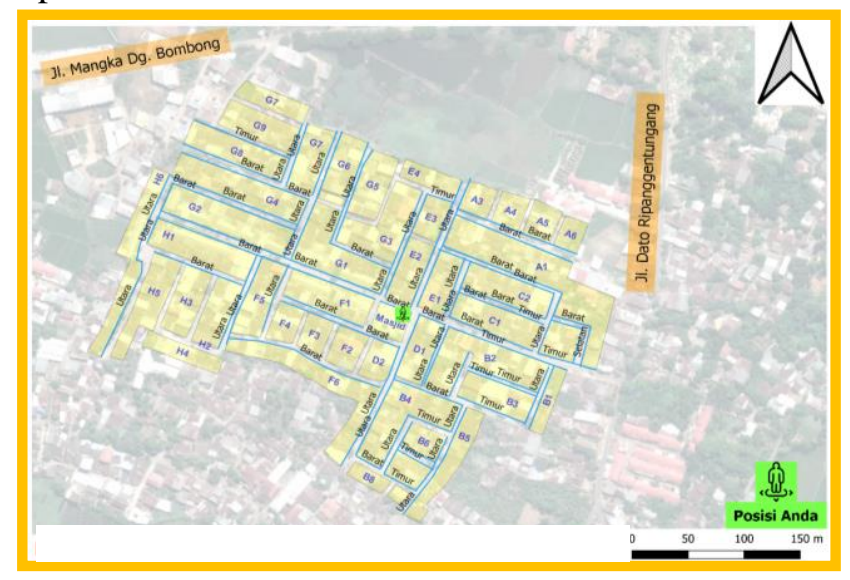

Gambar 2. Peta arah aliran air

\section{B. Berkurangnya Genangan Air pada Drainase}

Drainase pada perumahan tamarunang indah I selama ini tidak berfungsi sebagaimana mestinya. Arah aliran yang tidak jelas, genangan air yang terjadi serta banyaknya drainase yang tertimbun berdampak pada kerusakan jalan lingkungan serta menjadi sarang nyamuk yang dapat berdampak buruk terhadap kesehatan.

Adapun kegiatan yang dilakukan dalam rangka peningkatan fungsi drainase adalah:

1. Pembuatan lubang biopori

2. Pembuatan kolam Resapan

3. Pembuatan plat penutup saluran

4. Penataan taman di atas saluran

Pemasangan pipa biopori, air yang meluap dan menggenang di jalan raya dan di halaman rumah masyarakat menjadi berkurang. Dengan adanya pipa biopori, air hujan tidak menyebabkan genangan air di jalan dan dibagian hilir daerah perumahan. Hal ini sejalan dengan beberapa hasil studi menunjukkan bahwa penerapan drainase 
resapan merupakan salah satu metode drainase yang berwawasan lingkungan. (Harmani \& Soemantoro, 2017; Muliawati, 2015; Sudarmanto, 2010)

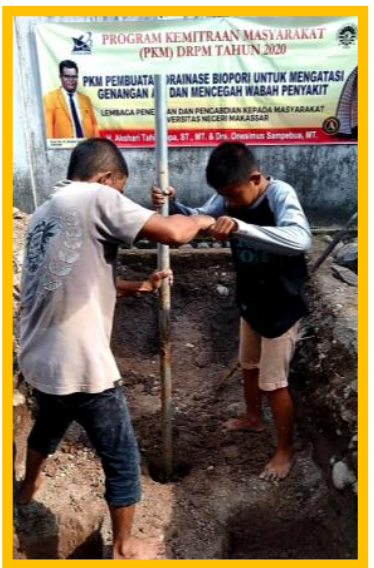

(a)

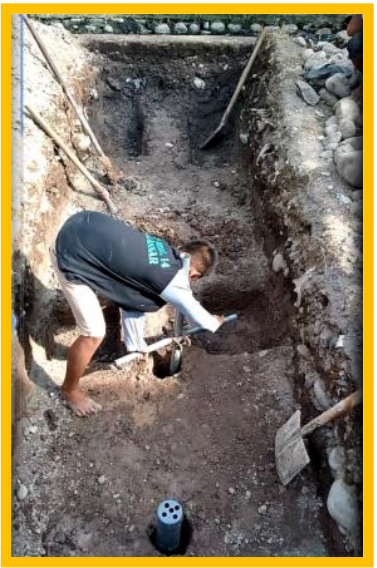

(b)
Gambar 3. Pembuatan lubang biopori

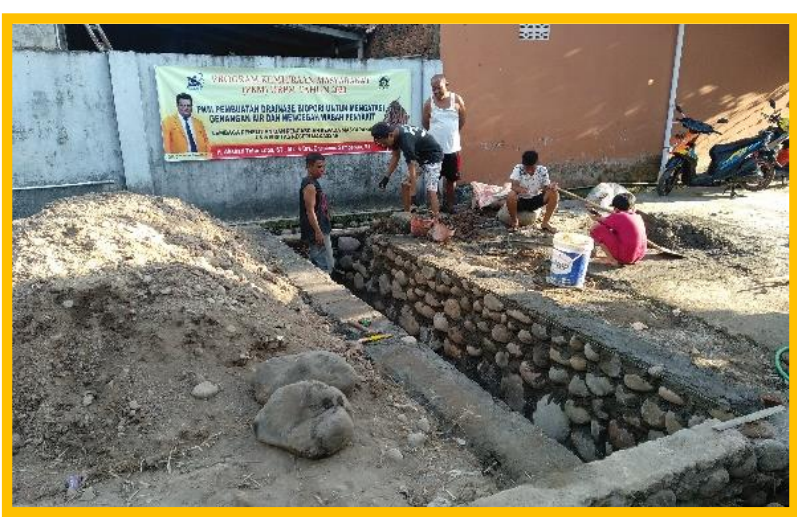

Gambar 4. Pembuatan kolam resapan

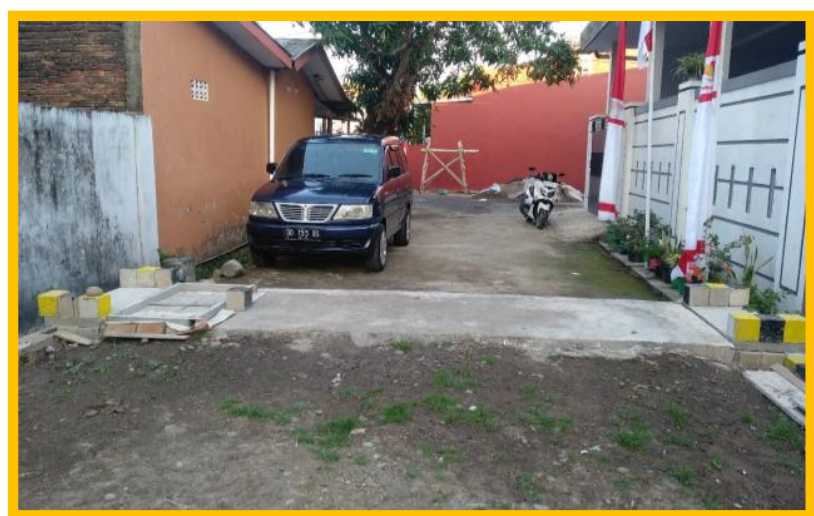

Gambar 5. Kolam resapan yang telah jadi

C. Penataan kembali saluran drainase

Pada perumahan Tamarunang diadakan juga pembuatan aliran saluran drainase karena pada daerah perumahan saluran drainasenya boleh dikatakan sudah rusak parah karena sudah rata dengan jalan sehingga menyebabkan air got meluap ke jalanan. Karena dengan adanya kerusakan tersebut maka dibuatkan saluran drainase agar aliran air tidak terhambat yang dapat menyebabkan air meluap ke jalan raya.

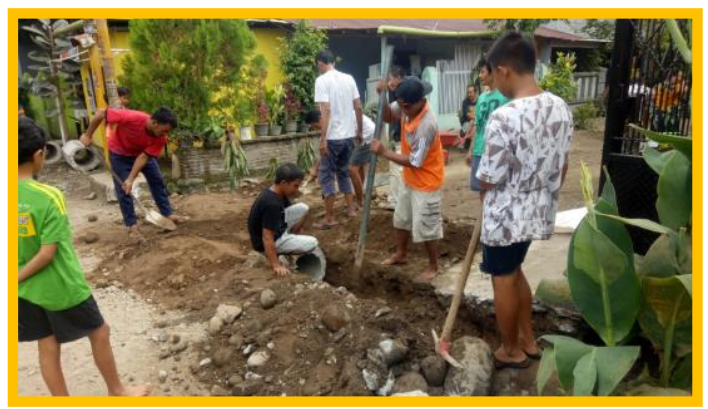

Gambar 5. Gotong royong penataan saluran

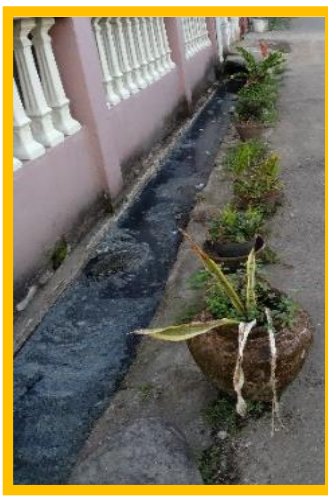

(a)

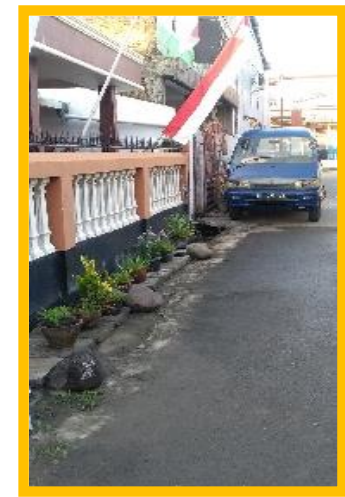

(b) (a) Saluran drainase sebelum penataan

(b) Saluran drainase setelah penataan

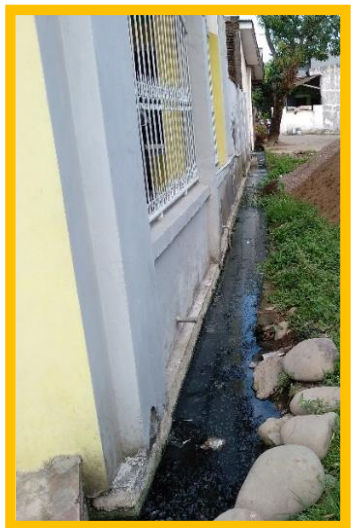

(a)

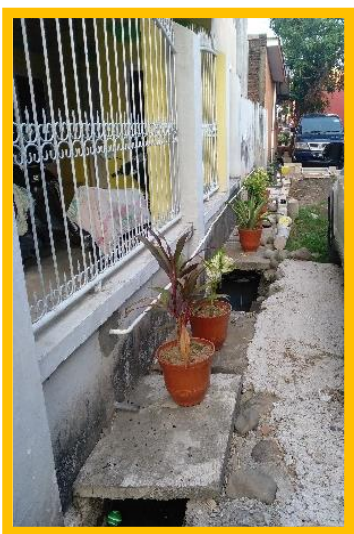

(b) (a) Saluran drainase sebelum diberi penutup (b) Saluran drainase setelah diberi penutup 
D. Kesadaran masyarakat memelihara drainase

Peningkatan kesadaran masyarakat menjadi salah satu indikator keberhasilan kegiatan PKM ini. Kegiatan diskusi awal dan pertemuan intensif yang dilakukan oleh tim pelaksana dengan pemerintah setempat termasuk ketua RT dan RW mendapat respon yang positif. Pelaksanaan gotong royong yang dilakukan oleh warga menjadi salah satu bukti keberhasilan pelaksanaan PKM.

Dampak ekonomi yang diperoleh dari kegiatan ini adalah:

1. Warga tidak lagi mengeluarkan biaya pembersihan ketika terjadi banjir

2. Tidak terjadinya biaya perbaikan rumah yang dapat rusak ketika terjadi genangan air yang lama

3. Biaya perbaikan dan penataan drainase tidak lagi dibebankan kepada warga, namun bersumber dari anggaran Kementerian Riset dan Teknologi / Badan Riset dan Inovasi Nasional (Ristek/ BRIN)

Dampak sosial yang diperoleh dari kegiatan ini adalah:

1. Meningkatkan pemahaman warga mengenali lingkungan sekitarnya

2. Meningkatnya semangat gotong royong warga mengatasi persoalan di lingkungannya

3. Menghindarkan terjadinya wabah penyakit akibat genangan air drainase

\section{PENUTUP}

1. Pembuatan peta arah aliran air drainase sebagai panduan dalam kegiatan pemeliharaan drainase oleh pemerintah setempat maupun warga melalui kegiatan gotong royong

2. Genangan air yang terjadi pada saluran drainase dapat diatasi dengan pembuatan lubang biopori pada dasar saluran drainase

3. Pada beberapa titik elevasi dasar saluran yang sulit mengalirkan air, dibuatkan kolam resapan yang berfungsi sebagai polder untuk menampung air genangan yang dibuat secara tertutup agar tidak menjadi sarang nyamuk

\section{UCAPAN TERIMA KASIH}

Tim pelaksana kegiatan mengucapkan terima kasih kepada Direktorat Riset dan Pengabdian kepada Masyarakat (DRPM) atas hibah program kemitraan masyarakat yang diberikan sehingga kegiatan ini terlaksana dengan sangat baik.

\section{DAFTAR PUSTAKA}

Asrib, A. R., \& Arfandi, A. (2019). Perumahan Tamarunang dalam memelihara drainase lingkungan. Seminar Nasional Pengabdian Kepada Masyarakat, 2018(2).

Chu, M. L., Knouft, J. H., Ghulam, A., Guzman, J. A., \& Pan, Z. (2013). Impacts of urbanization on river flow frequency: A controlled experimental modeling-based evaluation approach. Journal of Hydrology, 495, 1-12.

Florince, F., Arifaini, N., \& Adha, I. (2016). Studi Kolam Retensi sebagai Upaya Pengendalian Banjir Sungai Way Simpur Kelurahan Palapa Kecamatan Tanjung Karang Pusat. Jurnal Rekayasa Sipil Dan Desain, 3(3), $507-520$.

Harmani, E., \& Soemantoro, M. (2017). Kolam Retensi Sebagai Alternatif Pengendali Banjir. Jurnal Teknik Sipil Unitomo, 1(1).

Isik, S., Kalin, L., Schoonover, J. E., Srivastava, P., \& Lockaby, B. G. (2013). Modeling effects of changing land use/cover on daily streamflow: an artificial neural network and curve number based hybrid approach. Journal of Hydrology, 485, 103-112.

Maryono, A. (2020). Memanen Air Hujan. UGM PRESS.

Muliawati, D. N. (2015). Perencanaan Penerapan Sistem Drainase Berwawasan Lingkungan (Eko-Drainase) Menggunakan Sumur Resapan Di Kawasan Rungkut. Institut Technology Sepuluh Nopember.

Sudarmanto, B. (2010). Sistem Drainase Perkotaan yang Berwawasan Lingkungan. Prosiding SNST Fakultas Teknik, 1(1). 